\title{
Sexualidad perseguida y monjas embarazadas en el Virreinato de Perú a inicios del siglo XVII
}

\section{Persecuted sexuality and pregnant nuns in the Viceroyalty of Peru at the beginning of the $17^{\text {th }}$ century}

\author{
FRANCISCO JOSÉ GARCÍA PÉREZ \\ IEHM, Universitat de les Illes Balears \\ garcia.franj@hotmail.com
}

Resumen: Este artículo pretende estudiar el quebrantamiento de la clausura que se dio en distintos cenobios femeninos del virreinato del Perú a inicios del siglo XVII. A lo largo de esos años, los obispos postridentinos tuvieron que hacer frente a una realidad incómoda: episodios de sexualidad activa en numerosos monasterios femeninos y, en consecuencia, la existencia de monjas embarazadas. Analizando el caso de tres monasterios situados en las ciudades de Quito y Popayán, se intentará evidenciar en estas líneas cuáles eran los límites del Concilio de Trento y, al mismo tiempo, poner énfasis en las estrategias que gran número de monjas desarrollaron para ocultar todo rastro de sus infracciones monásticas.

Palabras clave: Monjas, obispos, clausura, Perú.

\begin{abstract}
This article seeks to study the breakdown of the closure that occurred in different female monasteries in the Viceroyalty of Peru at the beginning of the $17^{\text {th }}$ century. During those years, the post-Tridentine bishops had to dealt with an uncomfortable reality: episodes of active sexuality in many women's monasteries and, consequently, the existence of pregnant nuns. Analysing the case of three monasteries located in the cities of Quito and Popayán, we will try to show in these lines which were the limits of the Council of Trent and, at the same time, to underscore the strategies that a great number of nuns developed to hide all trace of their monastic infractions.
\end{abstract}

Keywords: Nuns, bishops, closure, Peru.

Recibido: 18 de diciembre de 2019; aceptado: 10 de octubre de 2019; publicado: 31 de marzo de 2020. Revista Historia Autónoma, 16 (2020), pp. 53-70

e-ISSN: 2254-8726; https://doi.org/10.15366/rha2020.16.003 


\section{La clausura femenina entre la excepción y la norma}

El Concilio de Trento había regulado al detalle el modo de vida que debían practicar las órdenes religiosas ${ }^{1}$. A partir de ese momento, primaron cuatro líneas maestras que marcarían el día a día de las comunidades femeninas: los votos de pobreza, obediencia, castidad y clausura ${ }^{2}$. En efecto, Trento consideraba prioritario forzar a las monjas a recluirse en sus respectivos cenobios, abandonar todo contacto con el mundo exterior y dedicarse a una vida de oración y trabajo ${ }^{3}$. Junto con esto, se hacía hincapié en la vida comunitaria, a menudo abandonada por religiosas que preferían pasar los días rodeadas de lujos en sus celdas y estar acompañadas por su servicio doméstico, la mayoría de las veces compuesto, en el caso americano, por esclavas negras o criadas indias ${ }^{4}$. Como muchos historiadores han señalado ya, la implantación de los postulados tridentinos no fue fácil y estuvo siempre sometida a discrepancias, disputas y reticencias 5 .

Por supuesto, la América española no fue ninguna excepción, y esto por varias razones. Dejando de lado que hubo vocaciones sinceras, con mujeres que voluntariamente se entregaron a la vida contemplativa y siguieron los pasos de algunos de los grandes modelos de santidad femenina, muchas otras se vieron forzadas a ingresar en los monasterios contra su voluntad ${ }^{6}$. La elevada mortalidad masculina como consecuencia de la conquista, las enfermedades o las revueltas que poblaron la primera mitad del siglo XVI, además de las dificultades para pagar la dote del casamiento - sensiblemente más elevada que la que se pagaba para ingresar en un monasterio - o las presiones familiares para deshacerse de bocas que alimentar, sin duda contribuyeron a engrosar las filas del clero femenino.

De modo que, durante la segunda mitad del Quinientos, se experimentó un progresivo aumento de fundaciones por todo el territorio hispanoamericano que, por supuesto, también

\footnotetext{
${ }^{1}$ Véase Sánchez Lora, José Luis, Mujeres, conventos y formas de religiosidad barroca, Madrid, Fundación Universitaria Española, 1988.

${ }^{2}$ Fernández Terricabras, Ignasi, "La influencia del Concilio de Trento en las reformas descalzas", en LibrosdeCorte. es, 9 (2014), p. 82.

${ }^{3}$ Véase Toquica, María Costanza, "Los votos de Obediencia, pobreza, castidad y clausura", en Revista Colombiana de Antropología, 37 (2019), pp. 159-186.

${ }^{4} \mathrm{La}$ atención que por lo general recibían las monjas en los sínodos celebrados en las distintas diócesis de Indias era bastante limitada. La mayoría de las veces las religiosas eran sacadas a raíz de dos ejes esenciales, que fueron reiteradamente demandados por los respectivos prelados, conscientes de que, en ocasiones, no se cumplían: un asunto todavía inconcluso era la observancia de la clausura, con continuos ejemplos de que se rompía una y otra vez. La otra cuestión para tratar eran los problemas económicos que experimentaban numerosos monasterios de monjas. Viforcos Marinas, María Isabel, "Las monjas en los concilios y sínodos celebrados en las iglesias del virreinato peruano durante la época colonial", en Viforcos Marinas, María Isabel y Campos Sánchez-Bordona, María Dolores (coords.), Fundadores, fundaciones y espacios de vida conventual: nuevas aportaciones al monacato femenino, León, Universidad de León, 2005, pp. 683-704.

${ }^{5}$ Véase Atienza López, Ángela, "Las grietas de la clausura tridentina. Polémicas y limitaciones de las políticas de encerramiento de las monjas... Todavía con Felipe IV”, en Hispania, 74248 (2014), pp. 807-834. https://doi. org/10.3989/hispania.2014.024

${ }^{6}$ Evangelisti, Silvia, Storia delle monache, Bologna, Il Mulino, 2012, p. 51.
} 
afectó a ciudades como Quito o Popayán ${ }^{7}$. Cada uno de estos cenobios estaba sujeto a una regla y quedaba bajo jurisdicción externa ${ }^{8}$. Algunos dependían directamente del provincial de la rama masculina de la orden, mientras que muchos otros, especialmente tras la clausura del Concilio, estaban tutelados por el ordinario diocesano'. Por lo tanto, la figura de la priora o abadesa se hallaba cargada de cierto poder de actuación, pero siempre tras los muros conventuales, vigilando en todo momento el cumplimiento estricto de los preceptos tridentinos entre los miembros de su comunidad. En especial, debía velar por el comportamiento ejemplar, la correcta realización de las tareas, la asistencia general a las ceremonias religiosas y, especialmente, el cumplimiento escrupuloso de la clausura ${ }^{10}$. Un peso enorme que recaía directamente sobre sus hombros, pues, como decía en 1717 el teólogo moral español fray Antonio Arbiol:

La indigna prelada que no cele en sus súbditas tan graves daños debe tener su condenación eterna, [...] porque en el severo Tribunal de Dios ha de dar estrecha cuenta de las almas de sus súbitas que se le perdieren por su culpa. ${ }^{11}$

Por otro lado, la misma arquitectura de aquellos edificios de nueva planta había sido planificada, precisamente, para contribuir a la clausura y la vida en común. Teniendo presente que la amplia mayoría de monasterios y conventos americanos se fundaron durante o después de la celebración de Trento, podrá comprenderse mejor su diseño específico. Rodeados de altos muros, disponían de zonas comunes como el claustro, el refectorio o, por supuesto, la iglesia, donde las monjas se reunían en oración o para el oficio de la misa ${ }^{12}$. Sin embargo, esta predisposición hacia la vida de clausura, tanto por su misma estructura arquitectónica como por los preceptos tridentinos, no siempre fue contestada con una aceptación tácita por parte de las comunidades de religiosas ${ }^{13}$. Todo lo contrario, ya en España hubo fuertes impedimentos y frenos para evitar que la clausura se convirtiese en una realidad. De hecho, el reinado de Felipe II se vio poblado de incidentes, con innumerables comunidades de religiosas que se negaban a someterse ${ }^{14}$.

\footnotetext{
${ }^{7}$ Borges, Pedro, Religiosos en Hispanoamérica, Madrid, Colecciones Mapfre 1492, 1992, p. 269.

${ }^{8}$ Fraschina, Alicia, "Reformas en los conventos de monjas de Hispanoamérica, 1750-1865: cambios y continuidades", en Hispania Sacra, 60 (2008), p. 447. https://doi.org/10.3989/hs.2008.v60.i122.63

${ }^{9}$ Borges, Pedro, Religiosos... op. cit., p. 275.

${ }^{10}$ Sobre las características del modelo de abadesa en el México colonial véase Lavrin, Asunción, Las esposas de Cristo. La vida conventual en la Nueva España, México D. F., Fondo de Cultura Económica, 2016, p. 175.

${ }^{11}$ Arbiol, fray Antonio, La religiosa instruida, Libro I, Madrid, imp. Real de la Gaceta, 1717, p. 177.

${ }^{12}$ La idea de clausura puede constatarse ya en la Europa medieval. De hecho, las comunidades religiosas mendicantes, en especial las hijas de Santa Clara, ya predispusieron el mantenimiento de la clausura, la vida en común y el desarrollo de una vida de humildad y pobreza. El Concilio de Trento únicamente asumió la clausura no ya como una excepción, sino como un deber que debía hacerse extensible a todas las órdenes religiosas femeninas. Sobre el modo de vida de las clarisas durante la Edad Media, véase Rodríguez Núñez, Clara Cristela, "El conventualismo femenino: las Clarisas", en De la Iglesia Duarte, José Ignacio, García Turza, Francisco Javier y García de Cortázar, José Ángel (coords.), IV Semana de Estudios Medievales, Nájera, Instituto de Estudios Riojanos, 1995, pp. 87-100. ${ }^{13}$ Mendoza Pérez, Jesús Leticia, "El mundo novohispano del siglo XVII: claustro de la mujer criolla", en Revista Géneros, 33 (2004), p. 61.

${ }^{14}$ Véase Gómez García, María del Carmen, "Los conflictos en la clausura femenina de la Málaga Moderna”, en Mestre Sanchís, Antonio y Enrique Giménez López (eds.), Disidencias y exilios en la España Moderna, Alicante, 1997, pp. 81-89; Intxaustegi Jauregi, Nere Jone, "Rebelión de las clarisas vizcaínas frente al Concilio de Trento",
} 
En la América colonial, la situación no fue muy distinta. Eran muchos los elementos que predisponían a quebrantar la clausura en los monasterios de monjas. Primeramente, muchas de ellas no estaban dispuestas a abandonar sus lujos y vivir una vida de pobreza y humildad. La mayoría de las constituciones y reglas remarcaban la necesidad de que "las que tenían alguna cosa en el siglo, cuando hubieren entrado en el monasterio de buena gana quieran que aquello sea común"15. Además, otro problema era aceptar plenamente el abandono voluntario del mundo exterior para dedicarse a una vida totalmente contemplativa y aislada tras aquellos gruesos muros ${ }^{16}$. Pero, si hubo un asunto que preocupó enormemente a los obispos de la Contrarreforma, fue la violación del voto de castidad.

Uno de los modos más comunes de que las monjas se viesen arrebatadas de la pureza, que tanto se exaltaba desde los púlpitos y también en los manuales moralizantes, se daba durante el acto de la confesión. El sacramento de la penitencia había quedado estrictamente regulado en el Concilio de Trento, pues la sombra de la solicitación llevaba siglos acechando el espacio del confesionario ${ }^{17}$. De hecho, Trento mandaba a las monjas a que "confiesen sus pecados a lo menos una vez en cada mes, y reciban la sacrosanta Eucaristía para que tomen fuerzas con este socorro saludable, y venzan animosamente todas las tentaciones del demonio"18. Para tal fin, obispos y superiores regulares designaban a un confesor ordinario que debía acudir a los monasterios femeninos bajo su jurisdicción. Y era durante el sacramento de la confesión cuando, en ocasiones, se producían actos que la Iglesia llevaba persiguiendo desde días pretéritos ${ }^{19}$. Movidos por su deseo sexual y su influencia sobre mujeres que por lo general desconocían totalmente aquellas prácticas, algunos confesores se valían de su ascendiente para obtener favores sexuales ${ }^{20}$.

El mismo espacio del confesionario, uno de los pocos lugares que rompían con la idea de vida comunal y ofrecían cierta discreción, ayudaba también a generar una atmósfera de privacidad $^{21}$. Por eso, fray Raimundo Lumbier, futuro predicador real, insistía en los peligros que acechaban tras el mismo acto de la confesión: "cualquier movimiento y comienzo de estos,

en Labrador Arroyo, Félix (ed.), II Encuentro de Jóvenes Investigadores en Historia Moderna. Líneas recientes de investigación en Historia Moderna, Madrid, Universidad Rey Juan Carlos, 2015, pp. 93-104.

${ }^{15}$ Ribera Calderón, José, Regla y constituciones que por autoridad apostólica deben observar las religiosas del orden del Máximo Doctor, México, 1702, p. 2.

${ }^{16}$ Arenas Frutos, Isabel, "Nuevos aportes sobre las fundaciones de conventos femeninos de la orden concepcionista en la ciudad de México", en Viforcos Marinas, María Isabel y Loreto López, Rosalva (coords.), Historias compartidas, religiosidad y reclusión femenina en España, Portugal y América. siglos XVI-XIX, León, Universidad de León, 2007, p. 263.

${ }^{17}$ Véase Haliczer, Stephen, Sexualidad en el confesionario. Un sacramento profanado, Madrid, Siglo XXI, 1998.

${ }^{18}$ Sesión XXV, cap. V. Providencias de clausura y custodia de monjas. López de Ayala, Ignacio, El Sacrosanto y Ecuménico Concilio de Trento, Barcelona, Imp. Ramón Martín Indar, 1845, p. 337.

${ }^{19}$ Véase González Torres, Annia y Reyes Rodríguez, Adolfo Yunuen, "La noción de delito y pecado en casos de solicitación novohispanos: consideraciones sobre solicitantes a finales del siglo XVI y principios del XVII", en Esquivel Estrada, Noé Héctor (coord.), Pensamiento Novohispano, México, Universidad Autónoma del Estado de México, 2017, pp. 161-180.

${ }^{20}$ Sarrión Mora, Adelina, Sexualidad y confesión. La solicitación ante el Tribunal del Santo Oficio (siglos XVI-XIX), Madrid, Alianza Editorial, 1994, p. 57.

${ }^{21}$ Sobre las relaciones sexuales entre confesores y penitentes en la Edad Moderna véase Bilinkoff, Jodi, Related lives. Confessors and Their Female Penitents, 1450-1750, Ithaca, Cornell University Press, 2005. 
si es advertido y querido con plena advertencia, aunque pretenda parar en solo él, es ya pecado mortal"22. Y, del mismo modo, el franciscano mexicano fray Andrés Borda recordaba en su manual de confesores, escrito a inicios del siglo XviII, que:

Cualquier religiosa que mantuviere amistad dentro o fuera, que pase a inhonesta, está en estado de condenación e inabsoluble. [...] Ignorantísimo ha de ser el confesor que la absolviere porque si la tal amistad es adentro, está la religiosa en ocasión próxima de pecar. ${ }^{23}$

El padre Borda no exageraba, porque el Papado había considerado aquel asunto como una cuestión de vital importancia. Prueba de ello es que su persecución pasó en 1592 a estar oficialmente en manos de la Inquisición ${ }^{24}$. Es cierto, pese a todo, que este trasvase jurisdiccional fue paulatino y no se implantó en todos los territorios al mismo tiempo. De hecho, en el virreinato de Perú de inicios del Seiscientos, distintos obispos continuaron adjudicándose la tarea de erradicar la solicitación en sus respectivas diócesis ${ }^{25}$.

A finales del siglo XVI, el delito de la solicitación fue ampliamente debatido por diversos tratadistas y teólogos, pues incluía cuestiones difíciles de definir ${ }^{26}$. ¿Qué se consideraba como solicitación? ¿Qué actos por parte del confesor y la confesada eran reprensibles? ¿Debía haber contacto físico o eran ya censurables las palabras insinuantes? Esta enorme complejidad había llevado en 1622 al papa Gregorio XV, movido por su espíritu reformista, a publicar la bula Universi Dominici Gregis, en la que quedaban establecidas las características del delito de solicitación, valiéndose de aspectos muy generales que sirviesen para evitar excepciones ${ }^{27}$. Conversaciones demasiado sugerentes, cualquier contacto físico, insinuaciones directas o incluso el que el confesor solicitase favores sexuales a su confesada a través de una tercera persona estaban incluidos en el delito de solicitación ${ }^{28}$. De hecho, en los expedientes inquisitoriales de solicitación, uno de los aspectos más comunes y repetidos era el uso de palabras afectuosas, cariñosas y, en ocasiones, lascivas.

En lo que a las monjas se refiere, la solicitación iba más allá del acto de la confesión, ampliándose a cualquier comportamiento indecoroso que el confesor practicase dentro de los muros del monasterio ${ }^{29}$. Este punto es importante pues, muchas veces, los abusos se producían

\footnotetext{
${ }^{22}$ Biblioteca Nacional de Chile [BNC], ms. 43055, p. 9. Lumbier, fray Raimundo, Destierro de ignorancias: desengaños para todo genero de personas religiosas (y ay mucho para otras) y especialmente para monjas, Madrid, 1600.

${ }^{23}$ Borda, fray Andrés, Práctica de confesores de monjas, en que se explican los quatro votos de Obediencia, Pobreza, Castidad y Clausura, por modo de diálogo, México, ed. Ribera Calderón, 1708, p. 45.

${ }^{24}$ García Cárcel, Ricardo y Moreno Martínez, Doris, Inquisición. Historia crítica, Barcelona, Temas de Hoy. Historia, 2000, p. 299.

${ }^{25}$ García-Molina Riquelme, Antonio M., "Instrucciones para procesar a solicitantes en el tribunal de la Inquisición de México", en Revista de Inquisición, 8 (1999), p. 86.

${ }^{26}$ Sarrión Mora, Adelina, Sexualidad y confesión... op. cit., p. 57.

${ }^{27}$ Haliczer, Stephen, Sexualidad en el confesionario... op. cit., p. 76.

${ }^{28}$ González Marmolejo, Jorge René, Sexo y confesión: la Iglesia y la penitencia en los siglos XVIII y XIX, México D.F., Plaza y Valdés, 2002, p. 26.

${ }^{29}$ Lavrin, Asunción, Las esposas de Cristo... op. cit., p. 277.
} 
no solo en el confesionario, sino en otros lugares, siempre alejados de la vida de la priora o, en ocasiones, en connivencia con ella. De estos episodios se configuró la imagen de una religiosa muy distinta del icono de santidad que tan frecuentemente se ha descrito. Se trata, en palabras de Sánchez Ortega, de la "monja enamorada" ${ }^{30}$. Del mismo modo que había clérigos que olvidaban la profesión de sus votos, también hubo casos de monjas que, o bien forzadas a vivir una vida que no deseaban, o bien viéndose seducidas, se entregaban a una relación prohibida ${ }^{31}$. De hecho, este tipo de lances no siempre eran consecuencia de una agresión o abuso, sino que podía darse un acuerdo tácito entre ambas partes. El galanteo propio de la sociedad moderna también se contagió a los monasterios femeninos. Y, como puede suponerse, estas transgresiones de la vida monacal, sobre todo las que conllevaban actos sexuales, podían materializarse en embarazos no deseados, que suponían la prueba más clara y fehaciente del delito cometido ${ }^{32}$.

Fue precisamente en ciudades como Popayán y Quito donde se vivieron algunos de los casos más escandalosos de solicitación, amancebamiento y violación de la clausura que iban a producirse durante el siglo XVII americano ${ }^{33}$. En algunos monasterios de monjas se evidenciaron, por un lado, los límites de la Iglesia de la Contrarreforma, además de un sinfín de estrategias destinadas a ocultar todo rastro del quebrantamiento de la vida monástica. Por otro lado, se constatarían también los desesperados intentos de unos obispos decididos a cumplir con la voluntad de Trento y, especialmente, fortalecer su ascendencia y autoridad sobre el clero regular.

\section{Ocultando el pecado: relaciones sexuales y embarazos en los monasterios femeninos de Popayán y Quito}

Una vez clausurado el Concilio de Trento, su estela se expandió imparable, llegando al Nuevo Mundo e infiltrándose en todos los ámbitos de la sociedad colonial ${ }^{34}$. El episcopado indiano tenía en sus manos una tarea imponente, pues debía asegurarse de que las disposiciones

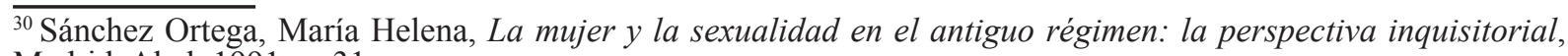
Madrid, Akal, 1991, p. 31.

${ }^{31}$ En efecto, los retratos hagiográficos de monjas son solo la cara de una misma moneda, y como dice Lavrin: "las monjas elegidas para formar parte de relatos hagiográficos, crónicas conventuales y sermones fúnebres ejemplificaban la cúspide de la perfección de sus órdenes. [...] Por el contrario, los casos documentados de las trasgresoras ilustran la realidad en el polo opuesto". Lavrin, Asunción, Las esposas de Cristo ... op. cit., p. 279.

${ }^{32} \mathrm{La}$ idea de la monja embarazada no era necesariamente nueva en el siglo xvI. La literatura castellana había presentado ya ciertos arquetipos de religiosas que habían incumplido sus votos monásticos, y como consecuencia se habían quedado embarazadas, en esencia la manifestación más evidente de sus propias culpas. La abadesa preñada, de Gonzalo de Berceo, es un arquetipo clásico, que evidencia su presencia en el imaginario popular. Véase Benito Vassels, Carmen, "Gonzalo de Berceo, el sacristán fornicario, la abadesa encinta y las Dueñas de Zamora", en Revista de Poética Medieval, 10 (2003), pp. 10-24.

${ }^{33}$ Véase Viforcos, María Isabel, "Luces y sombras de la vida monástica femenina: las concepcionistas de Cuenca (Ecuador) en el siglo XvIII", en Estudios Humanísticos, 17 (1995), pp. 311-328.

${ }^{34}$ Saavedra Inaraja, María, La forja del Nuevo Mundo. Huellas de la Iglesia en la América española, Madrid, ed. Sekotia, 2008, p. 95.
} 
tridentinas se cumplían a rajatabla. Para ejercer su autoridad, los prelados americanos - a semejanza de sus homólogos en Europa - disponían de diversos mecanismos y atribuciones para asegurarse de que no había trasgresiones ${ }^{35}$. De hecho, ningún regular podía actuar "sin licencia de su superior, sin que para esto le valga privilegio alguno, ni la licencia que con este objeto haya alcanzado de otros" ${ }^{\prime 36}$. Pero precisamente por esto, muchas veces, algunos religiosos trasgredían sus deberes, incluso en connivencia con sus superiores y provinciales. Una de las formas de violar sus votos era forzando o induciendo a las monjas a quebrantar también los suyos.

En las Indias, delitos como la solicitación o la violación de la clausura no fueron una excepción. Todo lo contrario, los obispos de los distintos virreinatos tuvieron que batallar sin descanso contra esta realidad desde antes de la celebración del Concilio de Trento. De hecho, para cuando los tribunales inquisitoriales impusieron su jurisdicción en este controvertido asunto, se encontraron ya con innumerables casos de clérigos que habían sido perseguidos por los prelados. Se constataba en muchos de esos informes la incapacidad del episcopado indiano por erradicar unos abusos que no solo se expandían imparables y se infiltraban en sus respectivas diócesis, sino que a menudo eran ensombrecidos y silenciados por la sociedad colonial ${ }^{37}$. Uno de los ejemplos más paradigmáticos fue el monasterio de la Encarnación de Popayán que, por supuesto, no fue el único, aunque sí uno de los que mayor resonancia tuvieron ${ }^{38}$.

Fundado en 1578 por el obispo fray Agustín de Coruña, el monasterio contaba con alrededor de treinta monjas agustinas al finalizar el siglo $\mathrm{XVI}^{39}$. Aunque Trento prodigaba una vida de pobreza y recato, muchas de ellas tenían criadas o esclavas y disponían de celdas individuales ${ }^{40}$. Y si bien la clausura, como decían las constituciones del monasterio, "se puso como guarda de la honestidad y cárcel espiritual de nuestra libertad, para nuestra mayor seguridad"41, no siempre era así. Todo lo contrario, a menudo las religiosas la quebrantaban intencionadamente. Además, hacia 1606, algunas de ellas habían solicitado formalmente que se las liberase de la jurisdicción

\footnotetext{
${ }^{35}$ Ya antes del Concilio, en la Castilla de Isabel I, hubo proyectos de reforma en numerosos monasterios de monjas dirigidos por el cardenal Cisneros, que marcaron la hoja de ruta para muchas de las nuevas fundaciones también en Indias. Véase García Oro, José y Pérez López, Segundo L., "La reforma religiosa durante la gobernación del cardenal Cisneros (1516-1518): hacia la consolidación de un largo proceso”, en Anuarium Sancti Iacobi, 1 (2012), pp. 47-174.

${ }^{36}$ Sesión XXV, cap. IV. Providencias de clausura y custodia de monjas. López de Ayala, Ignacio, El Sacrosanto y Ecuménico... op. cit., p. 336.

${ }^{37}$ Millar Carvacho, René, "El delito de solicitación... op. cit., p. 774.

${ }^{38}$ Sobre el monasterio de la Encarnación de Popayán contamos con los artículos de Méndez Valencia, que publicó en volúmenes sucesivos de Archivo Agustiniano. Véase Méndez Valencia, María Alexandra, "Aspectos de la historia documental del convento de Ntra. Sra. De la Encarnación de Popayán”, en Archivo Agustiniano, vols. 78-80, 1994-1996.

${ }^{39}$ Viforcos Marinas, María Isabel, "Las reformas disciplinares de Trento y la realidad de la vida monástica en el Perú virreinal”, en Ramos Medina, Manuel (coord.), Actas del II Congreso Internacional. El Monacato femenino en el Imperio Español. Monasterios, beaterios, recogimientos y colegios, México, Condumex, 1995, p. 532.

${ }^{40}$ Aunque las monjas agustinas no podían poseer bienes propios, en el monasterio de la Encarnación de Popayán muchas de ellas no deseaban verse privadas de ciertos lujos, que iban desde celdas ricamente ornamentadas a la posesión de esclavas para su servicio doméstico. Borges, Pedro, Religiosos... op. cit., p. 280.

${ }^{41}$ Coruña, fray Agustín, La sagrada regla del gran doctor de la iglesia N. P. San Agustin. Debaxo de la qual viven sus mongas ... Con las constituciones, $\bar{q}$ guarda el ... convento de religiosa agustinas, de la ciudad de Popayan, debajo del titulo ... de la Encarnacion, Lima, imp. Plazuela de San Cristóbal, 1756, p. 4.
} 
episcopal, aunque no alegaron las razones. Es muy posible que las visitas episcopales que se realizaban periódicamente constituyesen un problema, precisamente porque podían desvelar la compleja situación que se estaba viviendo tras los muros del monasterio. Por aquel entonces, ya se estaban produciendo excesos y abusos entre las religiosas que contaban con la connivencia de la priora, sor María Gabriela de la Encarnación, quien mantenía abiertamente una relación amorosa con un fraile de Santo Domingo. Un romance que ya era conocido por todas las habitantes de la Encarnación, acostumbradas a ver al dominico "dentro de la clausura entre las dos puertas reglares [...] a la cual [monja] la estaba abrazando y besando"42.

En 1608, la diócesis de Popayán se hallaba sin obispo y el deán de la Catedral, Juan de Montano, había sido elegido vicario general sede vacante. Tras conocer finalmente los rumores de que dos frailes del convento de Santo Domingo de la ciudad habían violado repetidas veces la clausura de las agustinas de la Encarnación, el deán cercó el monasterio y "no hallándolos por haberse escondido, me estuve quedo, y al medio día, dejando gente de guarda por la parte de

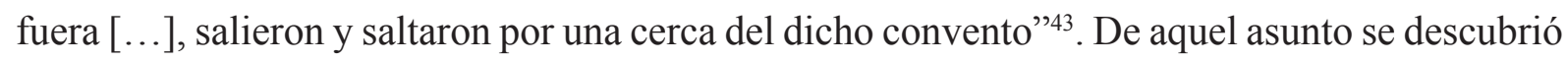
que tres monjas habían mantenido relaciones sexuales con ellos, entre ellas la misma priora, y que se habían convertido en sus "devotas"44.

Mientras el deán delegaba al provincial de los dominicos la responsabilidad de enjuiciar a los infractores, impuso al mismo tiempo un severo castigo a las tres monjas. En este caso, ordenó a la que había sido elegida nueva priora de la Encarnación que, "estando juntada la comunidad del dicho convento, sean sacadas de la cárcel y prisión en que están y sean llevadas al capítulo [...], vestidas con sus hábito y velo negro del cual serán despojadas y privadas”45. Sin embargo, la imposición de tales castigos no siempre se cumplía. En general, el clientelismo inherente a la sociedad moderna era una realidad que se vivía también dentro de los monasterios femeninos. De modo que las presiones que ejercieron los familiares de las monjas, infiltrados también en el Cabildo, forzaron a que "dentro de pocos días la sede vacante (con sola una carta simple de ellas) las mandó soltar [a las monjas] y volver los velos, porque de esta manera se procede por acá" ${ }^{46}$.

Pasados algunos meses de todo aquello, en 1609 llegó como obispo fray Juan González de Mendoza (1545-1617) ${ }^{47}$. Procedente del clero regular y miembro de la orden de San Agustín, el nuevo prelado se mostró desde el principio como un hombre intransigente y rígido, decidido a fortalecer la autoridad episcopal, vigilar el estricto cumplimiento de Trento y, al mismo tiempo,

\footnotetext{
$\overline{{ }^{42} \text { Archivo General }}$ de Indias [AGI], Audiencia de Quito, leg. 78, 32.

${ }^{43}$ AGI, Audiencia de Quito, leg. 80, 91.

${ }^{44}$ Sobre el concepto de monja "devota" véase Martínez Cuesta, Ángel, "Las monjas en la América colonial 1530-1824", en Thesaurus: Boletín del instituto Caro y Cuervo, 1-3 (1995), p. 606. https://doi.org/10.5840/ mayeutica199622541

${ }^{45}$ AGI, Audiencia de Quito, leg. 78, 32.

${ }^{46}$ AGI, Audiencia de Quito, leg. 78, 28.

${ }^{47}$ Véase Viforcos Marinas, María Isabel, "Semblanza de fray Juan González de Mendoza, embajador de Felipe II a China y obispo de Popoyán”, en Ciudad de Dios: Revista Agustiniana, vol. 211, 3 (1998), pp. 729-758.
} 
restaurar las empobrecidas arcas de la diócesis ${ }^{48}$. Uno de los asuntos que mayores quebraderos de cabeza le provocó, que le enemistó con gran parte de sus feligreses y que, si creemos en sus palabras, llegó a poner en peligro su vida, fue el sacrilegio cometido en el monasterio de la Encarnación.

Nada más poner sus pies en Popayán, González de Mendoza conoció de primera mano los acontecimientos de aquel monasterio de agustinas e indagó más a fondo en la cuestión. De hecho, no tuvo que esperar demasiado para saber que el asunto no estaba solucionado. Dirigiéndose a la Real Audiencia de Quito, de cuyo distrito dependía Popayán, el obispo solicitó que se abriese una investigación. Y para tal fin, se envió al oidor de la Audiencia, el licenciado Diego Zorrilla. Recién llegado a Popayán desde la ciudad quiteña en la Navidad de 1611, Zorrilla comprobó que la tarea no iba a ser fácil, "y como los culpados eran de la gente más granada del pueblo y las monjas estaban prevenidas y armadas, parecía imposible a los principios sacar cosa ninguna a luz" ${ }^{\prime 4}$. Siete esclavas negras del monasterio, y también testigos de los desmanes allí cometidos, habían sido ya expulsadas del mismo y las monjas se negaban a recibir al magistrado.

Residiendo en la ciudad, Zorrilla recopiló testimonios suficientes como para hacerse una idea clara de que "había en este convento la mayor perdición que jamás se ha oído" ${ }^{50}$. Lejos de limitarse aquellos abusos y excesos a tres monjas, muchas otras habían seguido los pasos de la antigua priora y eran devotas de frailes dominicos e incluso de vecinos de Popayán. El confesionario solía ser lugar de encuentros furtivos, los huertos del monasterio se habían convertido en escenario de apasionados romances, los muros — según parece más bajos de lo que se precisaba - se saltaban día y noche, y “contra alguno hay probado que lo tomó con tanto sosiego que habiendo entrado una noche se estuvo hasta la mañana de día durmiendo con la monja y fue menester echarle públicamente" 51 .

Como los magistrados de la Audiencia no podían entrar en los monasterios, Zorrilla reservó los días siguientes a reunir testimonios e informes, que cada vez clarificaban mejor la situación que allí se vivía. De hecho, mientras hacía sus pesquisas, supo por fuentes fidedignas que una de las monjas estaba de parto, "aunque no supo afirmarse en quien era el padre porque en el tiempo que se hizo preñada lo pudo ser más de uno"52. Finalmente, la Real Audiencia impuso castigos ejemplares a los principales culpables seculares: primero condenó a azotes a las esclavas que todavía permanecían en el monasterio y las desterró de Popayán. A continuación, fueron apresados algunos vecinos responsables de haber penetrado en la Encarnación, siendo dos de ellos condenados a la pena máxima. Y, finalmente, se delegó al obispo el castigo de

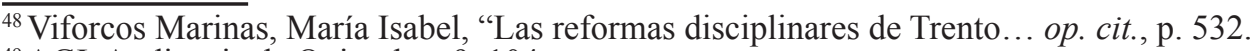

${ }^{49}$ AGI, Audiencia de Quito, leg. 9, 104.

${ }^{50}$ Ibídem.

${ }^{51}$ Ibídem.

${ }^{52}$ Ibidem.
} 
varios miembros del clero parroquial que habían colaborado con los dominicos en la violación de la clausura de aquellas monjas.

Pero González de Mendoza pronto vio que aquello no era suficiente. Si había un asunto que le perturbaba, y que todavía estaba pendiente, era el destino de las monjas del monasterio de la Encarnación. Los informes entregados por el oidor Zorrilla no le convencían y ya no confiaba en que las culpables hubiesen sido castigadas por la nueva priora electa. De modo que, en noviembre de 1612, el obispo se trasladó a la Encarnación acompañado de su sobrino y provisor, Diego de Mendoza, y de su secretario, a costa de los posibles peligros que, según creía él, le aguardaban, "lo uno por ser el tiempo de muchas aguas y crecientes de ríos y lo otro a que me la quiten [la vida] los delincuentes que han dejado volver allá, y las monjas y sus parientes" ${ }^{\prime 3}$. Una vez allí, desplegó un rigor desmesurado, organizando un tribunal episcopal y extrayendo testimonios de todas las religiosas ${ }^{54}$. Según parece, llegó a actuar con excesiva crueldad contra algunas de las inculpadas que se negaban a confesar, como fue el caso de la antigua priora, sor María Gabriela de la Encarnación, a la que "se le habían dado muy crueles [castigos] y de miedo y de los fieros, que el señor obispo les ponía y puso a esta testigo, que la había de matar en el tormento si no declaraba contra los dichos religiosos" ${ }^{55}$. De aquellos testimonios, y de los que los magistrados de la Audiencia habían arrancado ya a las esclavas y criadas, salieron a la luz todo tipo de escenas que quebrantaban los cuatro votos que regían el modo de vida del clero femenino ${ }^{56}$.

Un clérigo llamado Juan Sánchez había tenido a sor María de San Lorenzo como devota y "había tratado carnalmente con ella, y quitándole la virginidad en el aposento del torno" 57. De hecho, la entrada de frailes dominicos y laicos de Popayán se había convertido en más que recurrente, debido, primero, a que los muros del monasterio eran fácilmente escalables con una escalera, y también porque la priora abría la puerta del torno diariamente para dejar pasar a su amante y a sus compañeros de correrías. Como consecuencia de todo aquello, un número reseñable de monjas se habían quedado embarazadas. Por supuesto, las responsables intentaron ocultar a las criaturas recién nacidas de muy diversos modos, especialmente porque dentro del convento se respiraba un ambiente de facciones, entre aquellas que habían seguido a la priora y eran cómplices de los delitos de solicitación y violación de clausura, y aquellas pocas que se rebelaban contra la presencia de los dominicos en el monasterio y estaban dispuestas a todo para continuar bajo la autoridad episcopal.

La celda de la priora había terminado degenerando en una especie de improvisado paritorio. Asistidas por sus criadas y esclavas, las monjas que se ponían de parto debían acudir de inmediato a aquella estancia, que se presentaba como el único lugar seguro para ellas, con

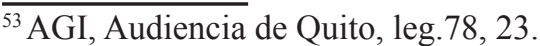

${ }^{54}$ Viforcos Marinas, María Isabel, "Las reformas disciplinares de Trento... op. cit., p. 533.

${ }^{55}$ AGI, Audiencia de Quito, leg. 86, 44.

${ }^{56}$ Martínez Cuesta, Ángel, "Las monjas en la América... op. cit., p. 606.

${ }^{57}$ AGI, Audiencia de Quito, leg. 78, 32.
} 
el mayor secretismo posible. Por eso mismo, cuando sor María de los Ángeles parió un niño en la celda de la priora, "hacían ruido de propósito las monjas de que en ella estaban porque no sintiesen en llorar al dicho niño"58. Tras el alumbramiento, se hacía imprescindible sacar al recién nacido del monasterio, eliminando así toda evidencia del delito cometido. En el mejor de los casos, el bebé era acogido por la familia de la monja o de cualquiera que quisiese hacerse cargo. Tenemos el ejemplo de sor Brígida de la Concepción, cuyas esclavas "aquella propia noche habían entregado la dicha criatura a Ana de Alegría, su madre, por la pared junto a la sacristía" 59 . O el de la misma priora sor María Gabriela de la Encarnación, que "parió un niño del dicho fray Diego de Guzmán y que lo llevaron [...] y entregaron a una mulata hija del cura" ${ }^{60}$, como confesó su esclava negra. Sin embargo, se daban también casos extremos motivados, muchas veces, por el miedo de la propia familia a caer en la deshonra pública. Eso ocurrió precisamente cuando "la ama que criaba la dicha criatura [de una monja] la había metido, porque lloraba, un palo por el sieso y la había muerto" ${ }^{" 61}$. Lo importante, llegados a este punto, es que las pruebas contra al menos quince monjas de la Encarnación eran demasiadas como para poder ocultarlas ${ }^{62}$.

Como el número de culpables y cómplices dentro del monasterio era tan elevado, y no podía confiarse en que la nueva priora hiciese frente a una situación tan desesperada, el obispo consideró que lo más oportuno era distribuir a las monjas entre diversos cenobios fuera de Popayán. De modo que, una vez terminado el controvertido juicio y recopilados testimonios suficientes, González de Mendoza mandó a su provisor que "las saquéis del dicho convento y repartáis por otros de esa provincia, las de Quito, Nuevo Reino y Perú, haciendo traer unas de otras partes [...] de buena vida y costumbres con cuyo gobierno, virtud y ejemplo se reparen los daños pasados" $"$. Mientras se elevaban los muros que rodeaban el monasterio, se clausuraron también todos los locutorios e incluso se cerró el torno, lo que dejaba a las religiosas allí encerradas hasta su definitivo traslado. Pero, además, el oidor de la Audiencia recibió noticias de que el prelado "tiene hecho un emparedamiento, donde dice que ha de poner a cuatro monjas las más culpadas y otras en el cepo" ${ }^{64}$. Pasarían muchos años antes de que las monjas de la Encarnación trasladadas pudiesen regresar a su monasterio. De hecho, la muerte de González de Mendoza no cambió el destino de aquellas religiosas. Hubo que esperar a 1631, cuando ocho

\footnotetext{
${ }^{58}$ Ibídem.

${ }^{59}$ Ibídem.

${ }^{60}$ Ibidem.

${ }^{61}$ Ibídem.

${ }^{62}$ Como han demostrado distintos historiadores, estas situaciones no fueron privativas del monasterio de la Encarnación, sino que se repitieron en otros muchos cenobios del virreinato del Perú, incluso cuando la Inquisición se adjudicó su persecución. Sobre las características de los clérigos solicitantes que fueron enjuiciados en el Perú véase González Marmolejo, Jorge René, “Clérigos solicitantes, perversos de la confesión”, en Ortega, Sergio (ed.), De la santidad a la perversión o de porqué no se cumplía la ley de Dios en la sociedad novohispana. Seminario de Historia de las Mentalidades, México, Grijalbo, 1985, pp. 239-252.

${ }^{63}$ AGI, Audiencia de Quito, leg. 78, 32.

${ }^{64}$ AGI, Audiencia de Quito, leg. 9, 109.
} 
de las quince monjas desterradas que todavía seguían con vida consiguieron por fin regresar, alcanzando el monasterio finalmente la cifra de sesenta profesas con sus respectivas criadas ${ }^{65}$.

Pese al escándalo que despertó el sacrilegio cometido en el monasterio de Popayán, más motivado por la publicidad que hizo el prelado que por los mismos excesos allí vividos, este no fue un caso singular. Todo lo contrario, mientras fray Juan González de Mendoza se trasladaba personalmente a la Encarnación para someter a las agustinas a un intenso juicio, el oidor de la Audiencia de Quito escribía a Madrid informando sobre la alarma que estaban despertando muchos otros religiosos, que "han introducido esta mala secta en las Indias, y los que tienen perdidos los conventos de monjas de esta ciudad [de Popayán] y los de Santa Clara y Santa Caterina de Sena de Quito" $"$.

La ciudad de San Francisco de Quito vivió también episodios similares. A inicios del siglo XVII, en distintos monasterios de monjas se estaban produciendo abusos que rompían claramente con los preceptos que Trento había establecido ${ }^{67}$. Y, aunque la solicitación en sí misma no era un asunto nuevo, sí que comenzó a preocupar enormemente al ordinario diocesano. De hecho, para cuando el obispo fray Salvador de Ribera y Dávalos (1545-1612) oyó los primeros rumores sobre los escándalos que estaban teniendo lugar entre el clero regular de la diócesis quiteña, la situación empezaba a volverse extrema. Siendo como era un hombre celoso y decidido, a la vez que carente de dulzura y misericordia cristianas, el prelado se propuso implantar la estela de Trento, pero valiéndose de una contundencia en ocasiones desmedida, a similitud del prelado payanense González de Mendoza.

En 1609, el provincial de los franciscanos, fray Gabriel Ramírez, envió un requerimiento al obispo Ribera informándole de que, tras su visita al monasterio de Santa Clara de Quito ${ }^{68}$, tenía intención de amonestar a "algunas religiosas del dicho convento, en que eran cómplices, y culpados algunos religiosos de la orden del glorioso Santo Domingo" "69. Según parece, el prior del convento dominico de San Pedro Mártir, fray Reginaldo Gamero, solía visitar a las clarisas de su ciudad y quebrantaba la clausura para pasar largas horas en compañía de la abadesa, sor Jerónima de San Antonio $^{70}$. Como informó posteriormente la vicaria del monasterio, "cerradas las puertas en este lugar podían los susodichos muy a su salud hacer todo cuanto malquisieren, por lo cual esta testigo tuvo por muy escandalosa esta amistad y que en este mismo compás almorzaban y merendaban"71. Pero no conformándose con mantener sus amoríos en privado, el padre Gamero se hacía acompañar también de otros dominicos que tenían devotas entre las clarisas del monasterio, y "los dichos religiosos se comunicaban con las dichas monjas como

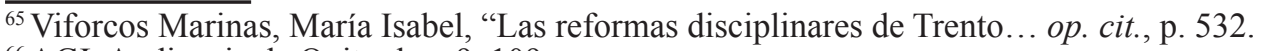

${ }^{66}$ AGI, Audiencia de Quito, leg. 9, 109.

${ }^{67}$ Martínez Cuesta, Ángel, "Las monjas en la América... op. cit., p. 606.

${ }^{68}$ Sobre los inicios del convento de San Clara de Quito véase Paniagua Pérez, Jesús, "Las décadas iniciales del monasterio de Santa Clara de Quito, reflejo de su medio (1596-1640)", en Archivo Ibero-americano, 229 (1998), pp. 127-144.

${ }^{69}$ AGI, Audiencia de Quito, leg. 77, 3.

${ }^{70}$ Sánchez Ortega, Helena, La mujer y la sexualidad... op. cit., p. 31.

${ }^{71}$ AGI, Audiencia de Quito, leg. 77, 3.
} 
tiene referido, las cuales en algunas ocasiones para verlos se ponían galanas y con gargantillas y otras galas" 72 . Organizando fiestas en el refectorio, las parejas allí congregadas se dedicaban a comer y a beber en un ambiente festivo que poco tenía que ver con el espíritu que se esperaba de unas hijas de Santa Clara.

Además de todo lo anterior, fray Reginaldo era también confesor de las monjas de Santa Catalina de Siena, en la misma ciudad de Quito. Habiendo seducido a la abadesa de las clarisas, no actuó con mayor tacto entre las dominicas ${ }^{73}$. Todo lo contrario, utilizaba el confesionario para solicitar favores sexuales y entablar relaciones amorosas que difícilmente podían ocultarse. De hecho, la fundadora y priora del convento, doña María de Silíceo, terminó descubriendo las actividades de fray Reginaldo Gamero y acudió personalmente al obispo Ribera "para remediar y castigar conforme al Concilio de Trento el gravísimo exceso y sacrilegio detestable que en el dicho mi convento ha cometido"74. Pues, continuaba la priora, el fraile había llegado al extremo de conseguir nublar las conciencias de sus confesadas, haciéndoles creer que los encuentros furtivos, las fiestas que celebraban en el refectorio y los amoríos que allí se estaban viviendo no eran motivo de inquietud. A fin de cuentas, siendo él su confesor, podía perdonarlas fácilmente ${ }^{75}$. Habiendo perdido el control total del monasterio, y con muchas de sus hijas actuando en total contubernio con fray Reginaldo, la priora se veía ya sin fuerzas para detener el caos que allí se respiraba.

Con las quejas del provincial de las clarisas y de la priora de Santa Catalina en sus manos, el obispo Ribera escribió directamente al provincial de los dominicos, fray Francisco García, exigiéndole que castigara al fraile solicitante. Pero fray Francisco era buen amigo del padre Reginaldo y simplemente dilató su respuesta, llegando a mentir para protegerle. Consciente de que su autoridad estaba siendo burlada, el obispo exigió alguna justificación de porqué "por ninguna vía ni camino ha podido saber ni entender que los religiosos hayan sido castigados, antes viendo lo contrario y que los dichos religiosos comprendidos en los dichos delitos están muy de asiento en esta ciudad" "76. Cuál fue su sorpresa cuando supo que fray Reginaldo Gamero no solo continuaba deambulando libre y sin castigo, sino que era el favorito para convertirse en el nuevo provincial de los dominicos. Contando con la protección del actual provincial y también de su amigo, fray Francisco García, ambos estaban asegurándoe su candidatura, lo

\footnotetext{
${ }^{72}$ Ibídem.

${ }^{73}$ El historiador fray José Vargas, de la orden dominica, intentó desmitificar los excesos cometidos por fray Reginaldo Gamero, especialmente porque sigue siendo recordado como un hombre de gran cultura y erudición. Vargas defendía que las acusaciones de solicitación contra el padre Gamero, que actuaba como confesor de las dominicas de Santa Catalina de Siena, eran fruto de una campaña de desprestigio orquestada por aquellos que no querían que se convirtiera en el nuevo provincial. Sin embargo, Vargas ignoraba que Gamero protagonizaba encuentros sexuales también con las clarisas, lo que deslustra la defensa que hizo de fray Reginaldo Gamero. Vargas, José María, "La verdad integral de sucesos históricamente desfigurados (1611-1612)", en Salvador Lara, Jorge (dir.), Historia de la Iglesia Católica en el Ecuador, Quito, Conferencia Episcopal Ecuatoriana, 2001, p. 1019-1029.

${ }^{74}$ AGI, Audiencia de Quito, leg. 77, 3.

${ }^{75}$ González Suárez, Federico, Historia general de la República de Ecuador. Tomo cuarto, Quito, Clásicos Ariel, 1969 , p. 39.

${ }^{76}$ AGI, Audiencia de Quito, leg. 77, 3.
} 
que suponía asumir el control total sobre el monasterio de Santa Catalina de Siena y librarse también de las iras del obispo Ribera, cada día más obcecado en desterrar de las Indias a ambos dominicos y reforzar su sombra sobre las dominicas de su diócesis.

Las censuras que el obispo Ribera y Dávalos lanzó sobre el padre García no cambiaron el rumbo de los acontecimientos y "lo eligieron por provincial [a fray Reginaldo Gamero], y habiéndose dado cuenta de todo ello y de la diferencia y duda de la elección a vuestro virrey, [el prelado] ordenó y mandó que el P. Fr. Reginaldo pareciese en la Ciudad de los Reyes"77. Los magistrados de la Real Audiencia, conscientes del cisma que se estaba viviendo en la ciudad de Quito, con el prelado declarando la guerra abierta a la orden de Santo Domingo, y fray Reginaldo Gamero alzándose como nuevo provincial, se vieron obligados a intervenir. De modo que el virrey autorizó al obispo Ribera a entrar en el monasterio de Santa Catalina, pese a la prohibición hecha por los dominicos, e interrogar a las monjas implicadas. Finalmente, el escándalo de aquel monasterio se hizo público y hubo pruebas suficientes para acusar a los frailes fray Reginaldo Gamero y fray Francisco García de solicitantes, quebrantadores de la clausura y sacrílegos. Y mientras el prelado declaraba oficialmente la destitución inmediata de Gamero como provincial y hacía colgar una orden de excomunión contra él en la puerta de las iglesias de la ciudad, desde España, Felipe III ordenaba al maestro general de Santo Domingo que eligiese inmediatamente a un visitador capaz de atajar el caos que se respiraba en Quito y devolver la disciplina y la cordura a los conventos y monasterios de la orden.

Con Gamero y García fuera de juego, en 1612 fue elegido visitador fray Juan de Ávalos. Al haber sido prior del convento de dominicos de Bogotá, y conocido por su celo excesivo y su vida austera, Ávalos parecía el candidato más apto para desempeñar las órdenes de su superior. Pero fue tal el rigor con que actuó que "contra todos ellos se ha querido hacer prelado ordinario y extraordinario en su modo de proceder, infamándoles por hacer algunas cosas públicas que pudieran ser secretas"78. Los métodos de Ávalos no casaban precisamente bien con las ya tradicionales violaciones de la vida religiosa que se vivían en los virreinatos de Indias, y que se habían convertido finalmente en un mal menor, que se consentía y se silenciaba no solo en beneficio de los infractores, sino también de sus respectivas familias y clientes.

En primer lugar, despojó del hábito a fray Reginaldo Gamero y lo condenó a las galeras de Cartagena, pero este había huido ya de Lima para salvarse de aquel castigo ${ }^{79}$. En cuanto a fray Francisco García, no tuvo tanta suerte y sufrió las iras del obispo y del visitador dominico. Llevado hasta la iglesia del convento de Santo Domingo, tuvo que soportar en silencio cómo fray Juan de Ávalos le arrebataba el hábito, lo degradaba ante un nutrido público y finalmente lo entregaba al brazo secular para que fuese condenado de por vida a galeras. Incluso habiendo sido responsable directo de los desmanes en los monasterios de monjas dominicas y clarisas,

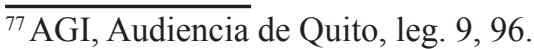

${ }^{78}$ AGI, Audiencia de Quito, leg. 80, 36.

${ }^{79}$ González Suárez, Federico, Historia general... op. cit., p. 39.
} 
despertó la lástima entre los feligreses de la ciudad, que demandaron su perdón sin resultados. Los mismos dominicos que habían suplicado a su maestro general que interviniera para detener la candidatura de fray Reginaldo como nuevo provincial terminaron escribiendo conjuntamente al rey para denunciar el supuesto gobierno tiránico que ahora ejercía el visitador en la ciudad de Quito. Según creían, Ávalos pretendía, “con una comisión limitada entablar jurisdicción plenaria y visitar toda la provincia, removiendo priores y quitando doctrinas donde es tan necesaria la jurisdicción de prelado legítimo" $"$.

Si hubo un lugar donde fray Juan de Ávalos actuó con excesivo rigor y dureza, despertando la sorpresa general, fue en el monasterio de Santa Catalina de Siena ${ }^{81}$. Mientras los padres Gamero y García eran públicamente vilipendiados, las monjas dominicas habían intentado liberarse de cualquier responsabilidad, esforzándose por oscurecer todos los desmanes que allí se habían cometido. Pero en esas mismas fechas, una de las monjas se puso de parto. Este hecho fue aprovechado por fray Juan de Ávalos y el mismo prelado, que "sacaron la criatura públicamente por la portería del convento y la llevaron a casa de la madre, con lo cual hasta los enemigos quedaron confundidos con este hecho venido de la providencia y ordenación divina" $\$ 2$. Finalmente, y a semejanza de lo que estaba ocurriendo con las monjas de la Encarnación de Popayán, las dominicas fueron severamente castigadas por quebrantar la clausura y haber violado su voto de castidad. Y, aunque las medidas de Ávalos para someter a las religiosas culpables no llegaron a los límites de las empleadas por el obispo de Popayán, sí que pueden considerarse extremadamente severas.

Como puede suponerse, delitos tan graves para el bienestar espiritual de los monasterios femeninos como la violación de la clausura, el quebrantamiento de la vida en común o la solicitación no desaparecieron de las ciudades de Quito y Popayán, como tampoco lo hicieron del resto de los territorios que conformaban el extenso virreinato de Perú. A lo largo del siglo XVII, estas cuestiones continuaron siendo severamente perseguidas por los respectivos obispos y los tribunales inquisitoriales, pero sin conseguir resultados eficaces. De hecho, llegado el Setecientos seguían firmemente arraigadas entre los miembros del clero indiano.

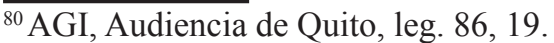

${ }^{81}$ El asunto de fray Reginaldo Gamero sirvió de base para que los obispos de Quito solicitasen a la Santa Sede que el monasterio de Santa Catalina de Sena quedase bajo su tutela. Las disputas entre prelados y dominicos para mantener sus prerrogativas sobre aquellas monjas dominicas se dilataron en el tiempo, y no fue hasta 1690 cuando el Papado falló en favor de que las religiosas continuasen agregadas jurisdiccionalmente a la orden de Santo Domingo. Martínez Cuesta, Ángel, Historia general... op. cit., p. 611.

${ }^{82}$ AGI, Audiencia de Quito, leg. 9, 92.
} 


\section{Conclusiones}

Los delitos de solicitación y violación de la clausura no fueron ninguna novedad en el siglo XVI. La Europa católica había testimoniado sobradamente su existencia a lo largo de la Edad Media. De hecho, la clausura no era practicada por todas las órdenes religiosas femeninas y únicamente algunas la habían implantado en su intento de reformarse. Al mismo tiempo, los obispos pretridentinos ya habían intentado perseguir el delito de solicitación, si bien, muchas veces, mostraron cierta permisión o se vieron incapaces de actuar. Todo ello generaba un mosaico preocupante, con innumerables trasgresiones de la vida monacal femenina que parecían haberse aclimatado profundamente. Por ese motivo, la idea de la clausura y la persecución de la solicitación recibieron una importancia caudal en el Concilio de Trento.

En sus sesiones, se debatió el modo de vida que debían profesar todas las órdenes religiosas femeninas, así como los medios más eficaces para perseguir los abusos y excesos que ya se habían vislumbrado en multitud de monasterios. Y si bien, en la España de Felipe II, muchas comunidades se negaban a abandonar el estatus que habían asumido al profesar los votos, en las Indias la situación fue relativamente distinta, precisamente porque un número importantísimo de monasterios y conventos femeninos se fundaron coincidiendo con la celebración del Concilio de Trento y también con su vasta reforma católica. Así se explica el hecho de que la misma arquitectura de aquellos cenobios se hubiese planificado teniendo muy presentes las ideas de clausura y vida en común. Dotados de altos muros y amplios espacios de convivencia, se pretendía que las monjas que allí vivían lo hicieran manteniéndose virtuosas y celosas, respetando los cuatro votos. Pero esto no quiere decir que la implantación de Trento en los distintos virreinatos fuese siempre sencilla. Aunque la idea de clausura no fue tan discutida como en España, hubo otros ámbitos que generaron mayor controversia. A menudo, las religiosas se negaban a verse privadas de los lujos que habían mantenido antes de profesar la vida monástica. Asimismo, la vida en comunidad era difícil de seguir, pues exigía el cumplimiento incuestionable de unos deberes y obligaciones fatigosos. Pero si hubo una trasgresión que cobró una importancia caudal para los padres conciliares y preocupó sobremanera a los papas del siglo XVII fue la solicitación. De hecho, la estricta regulación del sacramento de la confesión y la proliferación de manuales y tratados no erradicaron la presencia de clérigos solicitantes, que aprovechaban su autoridad para demandar favores sexuales a sus confesadas.

En lo que a este artículo se refiere, los monasterios estudiados de la Encarnación de Popayán, y Santa Clara y Santa Catalina de Siena en Quito recogen perfectamente los tipos de trasgresiones más usuales de la América de la Contrarreforma. De hecho, los tres casos tuvieron características muy similares, lo cual ofrece cierta extrapolación e indica que estas situaciones no fueron en absoluto privativas en el espacio y en el tiempo. En los tres casos, 
las religiosas acumularon múltiples faltas contra el espíritu de Trento y sus propias reglas o constituciones, entre las que se incluía la violación de la clausura, las relaciones sexuales y el abandono de la vida comunitaria. Pero más grave era el hecho de que todo aquello había sido permitido e incluso propiciado por una superiora. En la Encarnación y en Santa Clara se puede observar la colaboración implícita de la priora o abadesa, seducidas ambas por un dominico. Por supuesto, los amoríos o galanteos eran muy frecuentes en los monasterios. Lejos de tratarse únicamente de abusos sexuales, en ambos casos, las superioras se enamoraron de sus seductores y participaron conscientemente de aquellas transgresiones. A fin de cuentas, no todas las religiosas que tomaban los hábitos lo hacían por una decidida profesión religiosa, sino motivadas o forzadas por otras circunstancias. Esto explica la frecuente organización de fiestas en los locutorios y los encuentros furtivos en distintos lugares del monasterio. Unos desmanes que, no está de más añadir, no eran siempre extraños para los vecinos de las ciudades de Quito y Popayán. Pues, como se comprueba a raíz de los testimonios que los obispos recopilaron, muchos sabían lo que se estaba viviendo en los tres monasterios y lo toleraron durante años.

Esta resistencia "pasiva" a la reforma de cenobios femeninos se explica también por los fuertes lazos familiares y clientelares que primaban en la sociedad indiana. Muchas de aquellas religiosas estaban emparentadas en distintos grados con la élite payanense y quiteña, ya fuese con canónigos, magistrados de la Audiencia de Quito o algunos de los encomenderos más poderosos. Por eso mismo, una de las críticas más feroces que recibieron los obispos González de Mendoza y Ribera fue, precisamente, su poco tacto a la hora de tratar dichas cuestiones, lo cual equivalía a la excesiva publicidad que concedieron a los abusos protagonizados por las comunidades religiosas de Quito y Popayán. Actos como el traslado forzoso de quince monjas payanenses entre distintos monasterios o el paseo del bebé de una religiosa por las calles de Quito fueron ampliamente criticados porque se voceaba la falta de virtuosismo y honra de aquellas monjas. O lo que es lo mismo, se trataba de un ataque directo al apellido y la honra familiar y de su clientela. De aquí se desprende otra idea que debe tenerse presente, y es que la implantación de la reforma tridentina a menudo fue confundida en aquellos territorios con un autoritarismo desproporcionado que podía convertirse fácilmente en tiranía.

En los tres monasterios se repite un patrón a menudo incómodo para ciertos sectores historiográficos tradicionales. La mayoría de los delitos de solicitación y relaciones sexuales que en ellos se dieron, por lo que se desprende de los expedientes y la multitud de testimonios recopilados, fueron consentidos. La priora de la Encarnación y la abadesa de Santa Clara mantuvieron una relación amorosa y actuaron intencionadamente, inclinando a muchas de sus hermanas a participar también de aquellos excesos. Dejando de lado las razones que motivaban aquellas aventuras amorosas, lo importante de cara a este artículo, es que en algunos monasterios femeninos de la América colonial de principios del siglo XVII se mantenía una sexualidad activa que ni siquiera el Concilio de Trento pudo erradicar. La continua promulgación de leyes a lo 
largo de la centuria y los desesperados intentos del episcopado indiano y de la Inquisición por preservar los votos de castidad y clausura fue, en un sentido estricto, imposible. Numerosas religiosas cumplieron con sus deberes celosamente y se dedicaron a la vida que Trento había establecido para ellas, pero muchas otras se rebelaron ante aquella realidad y contribuyeron a engrosar los casos de resistencias a la vida monacal, siendo, muchas veces, víctimas de los severos castigos que la jerarquía eclesiástica tenía reservados para ellas.

Finalmente, la proliferación de embarazos que se dio en aquellos monasterios se tradujo en un arsenal de estrategias destinadas a ocultar la prueba más clara del quebrantamiento del voto de castidad: el recién nacido. De ese modo, las monjas embarazadas se valieron de un espíritu de camaradería y complicidad para disimular los inevitables partos que iban a producirse. La conversión de la celda de la priora de las agustinas de Popayán en un improvisado paritorio, el traslado de los bebés al exterior del monasterio o la expulsión del servicio doméstico implicado son solo algunos de los mecanismos más usuales. La idea que subyace es que la existencia de monjas embarazadas comenzó a cobrar una visión relativamente nueva en aquellas ciudades. Aunque oficialmente condenada y públicamente perseguida por los obispos, aquella imagen no fue ya del todo extraña, lo que se demuestra por el interés tanto de las monjas implicadas como de sus propias familias y amigos en disimular ante las autoridades aquella incómoda realidad. 